\title{
ANÁLISIS LONGITUDINAL DE LOS SITIOS WEB DE LAS ESTACIONES DE ESQUÍ Y MONTAÑA DE ESPAÑA, ANDORRA Y PIRINEO DE FRANCIA. TEMPORADAS 2009-10 Y 2013-14
}

\author{
Óscar García Lastra \\ Gregorio Escalera Izquierdo
}

Universidad Nacional de Educación a Distancia. Madrid.

\section{RESUMEN}

En el presente estudio se realiza un análisis longitudinal, entre las temporadas 2009-10 y 2013-14, de los sitios Web de las Estaciones de Esquí y Montaña de España, Andorra y Pirineo de Francia, adaptando el modelo eMICA (Extended Model of Internet Commerce Adoption) planteado por los autores Burgess y Cooper (2000) y adaptado por García y Escalera (2008). Un método de carácter exploratorio, que recoge las características y funcionalidades que el sitio Web de una estación de esquí y montaña debe tener. Los resultados son heterogéneos, y siguen mostrando un bajo grado de madurez funcional.

Palabras clave: Internet; Turismo; Destino; Sostenible; Estaciones de Esquí y Montaña; Sitio Web; eMICA.

\section{Longitudinal analysis of Websites of mountain and ski resorts in Spain, Andorra and Pyrenees of France. Seasons: from 2009-10 to 2013-14}

\section{ABSTRACT}

In this paper, is performed a longitudinal analysis of Websites Ski and Mountain resorts in Spain, Andorra and the Pyrenees in France, between 2009-10 and 2013-14 seasons, adapting the model $e M I C A$ (Extended Model of Internet Commerce Adoption) posed by Burgess

Recibido: 3 de octubre de 2015

Devuelto para su revisión: 16 de febrero de 2016

Aceptado: 14 de junio de 2016

Facultad de Ciencias Económicas y Empresariales. Universidad Nacional de Educación a Distancia. Paseo Senda del Rey, 11.Ciudad Universitaria.28040 MADRID (España).E-mail: osgsarlas@gmail.com, gescalera@cee.uned.es 
and Cooper (2000) and adapted by authors Garcia and Escalera (2008); an exploratory method which includes the features and functionality that the Website of a mountain and ski resort should have. The results are heterogeneous, and still show a low degree of functional maturity.

Keywords: Internet; Tourism; Destination; Sustainable; Ski and Mountain; Website; eMICA.

\section{INTRODUCCIÓN}

España sigue siendo un destino turístico de primer orden a nivel mundial, tanto por número de visitantes como por ingresos. El sector turístico español se ha caracterizado por ser uno de los motores económicos más potentes (Esteve y Fuentes, 2000), esta importancia se ha visto acrecentada al ser protagonista en la cohesión de los territorios, siendo en ocasiones una actividad monocultivo, con una dimensión económica y social. Pero este paisaje ciertamente idílico sigue ocultando algunos nubarrones como:

- Una oferta concentrada y estacional, con una elevada dependencia del turismo de sol y playa (OPTI, 2005); fomentar la desestacionalización ha sido siempre un objetivo prioritario en los planes para la promoción del turismo (TURESPAÑA, 2012). El mercado turístico está cada vez más segmentado en grupos de consumidores con intereses y necesidades diferenciadas, aumentando la demanda de forma más activa e individualizada (Aguiló et al., 2004); esto obliga a profundizar más en los nichos de mercado y responder a los nuevos estilos de vida, con tipologías de cliente más heterogéneas.

- Y una brecha tecnológica respecto a los países de nuestro entorno; el nivel de acceso a Internet en los hogares españoles está un $9 \%$ por debajo de la media europea en el año 2013, y en las compras online la brecha se mantiene en los últimos años por encima del 10\% (INE, 2014). Además de la baja cultura tecnológica (Mañá y Escobar, 2005), factores como el desconocimiento o la inseguridad explican este retraso (ONTSI, 2014). Hoy el viajero dispone de más información, accesible, rápida y global; todo o casi todo se encuentra al alcance de un clic. El rápido desarrollo de la tecnología de la información en general y de Internet en particular, ha cambiado radicalmente la industria del turismo (Ho y Lee, 2007), los productos más consumidos en la Red en el año 2013 siguen relacionados con el turismo (INE, 2014), por eso las nuevas tecnologías de las comunicación e información (en adelante TICs) se revelan como un factor de innovación clave en el desarrollo del turismo.

En este contexto, este trabajo además de realizar una valoración longitudinal de los sitios Web, tiene como objetivos específicos:

1) Poner en valor el turismo de nieve y montaña, con un alto impacto en las áreas geográficas de influencia. 
2) Destacar el sitio Web como instrumento canalizador de la información e interactividad con el usuario.

3) Repasar las metodologías utilizadas para evaluar sitios Web; y establecer un modelo sencillo y de gran utilidad para todos los actores implicados en este segmento turístico.

\section{EL TURISMO DE NIEVE}

El principal motivo que mueve a los turistas a realizar un desplazamiento, tanto a nivel mundial como en España, son el ocio y las vacaciones; en España representa un 87\% de los desplazamientos, en el resto del mundo un 52\% en el año 2013 (TURESPAÑA, 2015); le siguen los viajes por trabajo y negocios, y los vinculados a la familia, salud y otros. Unas motivaciones cada vez más diversas: cultura, ocio, vacaciones, naturaleza, historia, folklore o compras; algunas con un marcado carácter transversal.

También a partir de TURESPAÑA (2015) entre las actividades declaradas por los turistas recibidos, destacan las actividades culturales realizadas por más del $50 \%$, las actividades de diversión (20\%) y las actividades deportivas (13\%). En el segmento deportivo, sobresalen las actividades que se desarrollan al aire libre, en el entorno de la montaña, deportes náuticos o golf. Los turistas amantes del deporte eligen destinos que se corresponden con situaciones geográficas que reúnen las condiciones idóneas para practicar deporte (Montaner, 2001).

En el turismo de nieve y montaña, la motivación principal que causa el desplazamiento es practicar deportes relacionados con la nieve y la montaña, o asistir a competiciones o pruebas de carácter profesional o amateur (García y Escalera, 2008). El desarrollo de productos como el turismo de nieve abre nuevas posibilidades tanto de actividad como de estacionalidad para los destinos clásicos vacacionales (TURESPAÑA, 2007). Su impacto económico y social en el entorno es enorme, dinamiza y favorece el desarrollo de las zonas de influencia, bien como actividad principal, bien como actividad complementaria a otras. Gracias al papel que cumplen en el medio rural en el que se ubican, son elementos centrales para la vertebración de un territorio (Merinero y Navarro, 2010). Un peso que se visualiza en sistemas montañosos como los Alpes, donde realiza una importante contribución a la economía de los países alpinos (Abegg et al., 2007); o en los Pirineos, donde los datos ponen de manifiesto que el flujo de turistas hacia los Pirineos ha cobrado una importancia económica determinante (Carús, 2002).

\subsection{El turismo de nieve: impacto económico}

En España, son 31 las estaciones de esquí y montaña las que se encuentran asociadas bajo ATUDEM creada en 1974. En la temporada 2013-14, a pesar de una coyuntura económica adversa, recibieron 5,11 millones de visitantes, un 4,2\% más que en la temporada anterior.

A partir de ATUDEM (2015) se pueden apuntar algunos datos que nos muestran el peso del sector; en la temporada 2011-12 la aportación de las estaciones de esquí españolas a las 
comarcas de la montaña fue de 800 millones de euros, y casi 100.000 puestos de trabajo, sumando directos e indirectos; agrupando a un amplio e importante conjunto de recursos relacionados con sus instalaciones e infraestructuras: maquinaria, ropa, material, desarrollo urbanístico e inmobiliario, agencias de viajes, transporte, municipios, mancomunidades, regiones, restaurantes, hoteles, seguridad y otros.

\section{Figura 1}

\section{EVOLUCIÓN ESQUIADORES POR TEMPORADA EN ESPAÑA (EN MILLONES). PERÍODO 2007/08-2013/14}

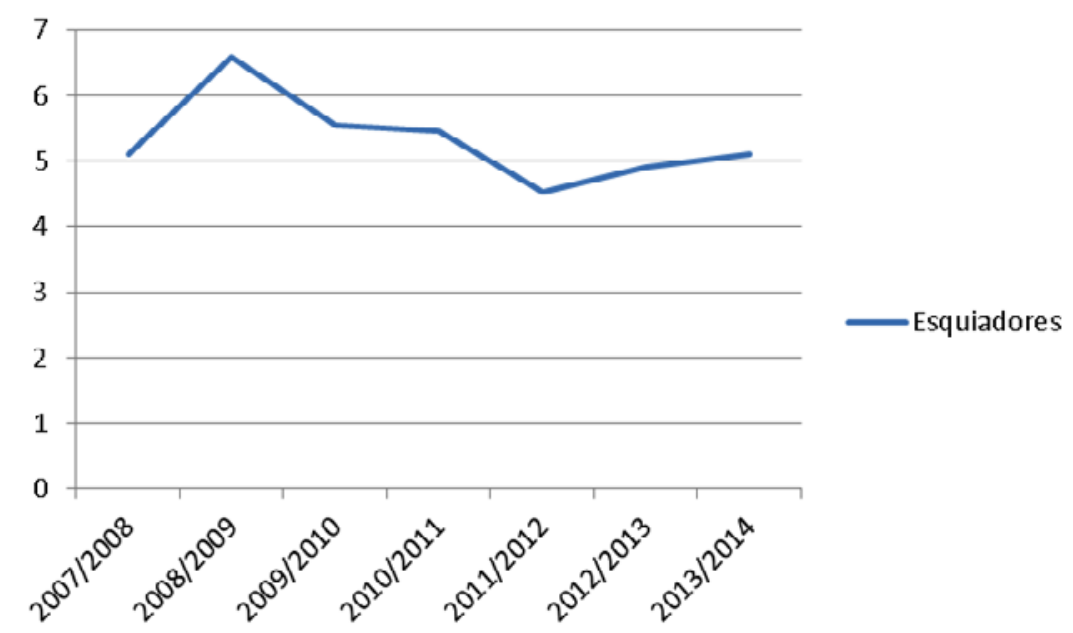

Fuente: Elaboración propia a partir de ATUDEM (2015).

Desde la demanda, si analizamos los días de esquí en el conjunto de Europa, destacan especialmente cuatro países: Francia, Austria, Italia y Suiza, que copan el $84,5 \%$ del total en la temporada 2013-14. Si nos centramos en los países que son objeto de análisis: Francia en su conjunto representa el 30\%, mientras que Andorra y España, el 1,2\% y 2,6\% respectivamente.

En España, la mayor parte de los esquiadores se agrupan en el Pirineo, en torno a tres millones de esquiadores por temporada, más que el resto de sistemas montañosos juntos. A su vez el Pirineo francés concentra el mayor número de esquiadores, seguido por el español y andorrano; sólo los Pirineos en Francia, con datos de la temporada 2012-13, tuvieron más días de esquí que todas las estaciones de esquí y montaña de España juntas; también es mayor su infraestructura, con 369 remontes y un total de 771 pistas, y un espacio nórdico de $800 \mathrm{Km}$ de pistas. Otro dato interesante de los Pirineos en Francia es la canalización de los recursos hacia diferentes actividades, más allá del esquí, como la raqueta de nieve, que representa el $61 \%$ de la cifra de negocios nacional, por encima incluso de otros macizos franceses como el alpino (PYRENEES, 2015).

Desde el lado de la oferta, en España ha habido un incremento en el alojamiento del $54 \%$ entre las temporadas 2003-04 y 2012-13, se han pasado de 126.427 a 195.000 plazas 
hoteleras, teniendo en cuenta un área de influencia de hasta $35 \mathrm{Km}$ en cada estación de esquí y montaña. Las inversiones en estos 10 años superan los 600 millones de euros, principalmente en infraestructuras: capacidad de transporte, kilómetros de pista, Snow Park o cañones de nieve artificial.

\section{Cuadro 1}

\section{CIFRAS EN LAS ESTACIONES DE ESQUÍ ALPINO. PERÍODO 2003/04-2012/13}

\begin{tabular}{|c|c|c|c|c|c|c|}
\hline Temporada & Remontes & Cañones & $\begin{array}{c}\text { Innivación } \\
(\mathbf{K m})\end{array}$ & $\begin{array}{c}\text { Capacidad } \\
\text { (viajeros/hora) }\end{array}$ & $\begin{array}{c}\text { Pistas } \\
(\mathbf{K m})\end{array}$ & $\begin{array}{c}\text { Snow } \\
\text { Park }\end{array}$ \\
\hline $\mathbf{2 0 1 2 - 2 0 1 3}$ & 361,0 & $4.500,0$ & 375,0 & $460.300,0$ & $1.039,0$ & 28,0 \\
\hline $\mathbf{2 0 1 1 - 2 0 1 2}$ & 361,0 & $4.399,0$ & 365,0 & $449.457,0$ & $1.026,0$ & 26,0 \\
\hline $\mathbf{2 0 1 0 - 2 0 1 1}$ & 362,0 & $4.315,0$ & 348,0 & $454.952,0$ & $1.011,0$ & 24,0 \\
\hline $\mathbf{2 0 0 9 - 2 0 1 0}$ & 364,0 & $4.245,0$ & 338,0 & $456.748,0$ & $1.007,0$ & 23,0 \\
\hline $\mathbf{2 0 0 8 - 2 0 0 9}$ & 378,0 & $4.450,0$ & 358,0 & $467.677,0$ & $1.036,0$ & 24,0 \\
\hline $\mathbf{2 0 0 7 - 2 0 0 8}$ & 378,0 & $4.350,0$ & 332,0 & $459.747,0$ & $1.001,0$ & 19,0 \\
\hline $\mathbf{2 0 0 6 - 2 0 0 7}$ & 350,0 & $4.271,0$ & 320,0 & $421.660,0$ & 952,0 & 11,0 \\
\hline $\mathbf{2 0 0 5 - 2 0 0 6}$ & 343,0 & $3.886,0$ & 292,0 & $398.182,0$ & 888,0 & 10,0 \\
\hline $\mathbf{2 0 0 4 - 2 0 0 5}$ & 341,0 & $3.687,0$ & 274,0 & $384.858,0$ & 887,0 & 5,0 \\
\hline $\mathbf{2 0 0 3 - 2 0 0 4}$ & 334,0 & $3.372,0$ & 243,0 & $358.916,0$ & 886,0 & 9,0 \\
\hline
\end{tabular}

Fuente: Elaboración propia a partir de ATUDEM (2015).

\subsection{El turismo de nieve: peculiaridades}

Aunque no forma parte de los objetivos específicos del estudio, si creemos necesario apuntar algunos rasgos distintivos del turismo de nieve y montaña:

- Ya hemos indicado que se desarrolla en un entorno natural, y que por sus características es altamente exigente en inversiones, infraestructuras y mantenimiento, por eso en pocas actividades turísticas es tan clave el aprovechamiento óptimo y equilibrado de los recursos naturales; se debe contar con una estrategia que contemple su maximización de forma sostenible, competitiva y rentable. Los tres pilares del turismo sostenible que permiten a los destinos garantizar su viabilidad a largo plazo son: el ecológico, el económico y el social (OMT, 2015). Destacamos en este punto, como 14 estaciones de esquí asociadas a ATUDEM, Asociación Turísticas de Estaciones de Esquí y Montaña, han obtenido el sello de Calidad Turística Española - Q (ICTE, 2015).

- Al condicionante físico y geográfico para seguir creciendo desde el lado de la oferta, hay que sumar el problema de la estacionalidad, que también se manifiesta en el turismo de nieve, donde las temporadas se pueden extender, en años buenos 
o muy buenos, desde el mes de diciembre al mes de abril. Hay que ofrecer actividades complementarias: deportivas (senderismo o bicicleta de montaña), culturales o gastronómicas, que amortigüen la temporalidad y maximicen los ingresos. Las regiones de montaña han de evolucionar de un turismo de masas a un turismo multi-nicho (CMTNM, 2014).

- Otra particularidad, no menos importante, es que la actividad que se realiza en las pistas y su entorno es principalmente deportiva, y que por su propia naturaleza entraña riesgos. Apenas existe una legislación que regule las actividades al aire libre, por lo que nos encontramos en un terreno en constante evolución (Ayora, 2008); en este ámbito hay Comunidades Autónomas que han regulado algunas materias como los transportes por cable por motivos de seguridad, el respeto al medioambiente o la accesibilidad para los discapacitados (BOCG, 2007); pero no hay todavía una normativa legal sobre la actividad que se desarrolla en una estación de esquí, actualmente sujeta a la regulación propuesta por ATUDEM y suscrita por las estaciones de esquí asociadas; un reglamento aprobado en 1994 y que ocho años después fue revisado y actualizado, para adaptarlo a las normas elaboradas por la Federación Internacional de Esquí (FIS) en 2002, principalmente en materia de seguridad.

\section{EL SITIO WEB}

El desarrollo de las TICs ha venido a revolucionar la forma en que los turistas planifican, organizan y realizan sus viajes. El uso de Internet es mayoritario entre los turistas llegados a España, un 65,6\% de los mismos han recurrido a este medio en la organización de sus viajes en el año 2013 (TURESPAÑA, 2015). El mayor uso se sigue dando para consultas, pero está creciendo en reservas y pagos, más del $50 \%$ de los usuarios de la red lo utilizan ya como forma de pago. A su vez, es ampliamente aceptado que Internet puede servir como una herramienta de marketing efectiva en el turismo (Buhalis y Law, 2008); el sitio Web se ha revelado como un instrumento clave para la comunicación de las marcas de destino y para la comercialización de todo tipo de servicios y productos relacionados con ellas (Fernández-Cavia y Huertas, 2009).

Cuando el destino es lo suficientemente relevante se acostumbra a crear una organización especialmente dedicada a promocionar el destino (Buhalis, 2000); las Organizaciones de Marketing de los Destinos (en adelante OMDs) se están dando cuenta de las posibilidades de Internet para promocionar sus áreas geográficas, productos y servicios (Gretzel et al., 2006). Internet es una extraordinaria oportunidad para fortalecer las marcas de destino; pero el hecho de tener un sitio Web no es, en sí mismo, garantía del éxito del destino (Palmer, 2005). Un destino turístico es un área geográfica donde se localizan recursos turísticos y hacia donde se desplazan los turistas (Hall, 2000); otros autores tienen un enfoque más transversal, y lo entienden como la amalgama de productos turísticos que ofrecen una experiencia integrada a los turistas (Buhalis, 2000). En esta línea una estación de esquí constituye por sí sola un destino turístico y su planificación debe tener en cuenta las sinergias de los recursos que tiene a su alcance. 


\section{METODOLOGÍAS DE ANÁLISIS WEB}

En el ámbito del turismo aún no existe una definición universalmente aceptada de qué es y en qué ha de consistir la evaluación de los sitios Web (Law et al., 2010), una herramienta fundamental en el esfuerzo de diseño de sitios Web informativos, eficaces y de calidad (Pallas y Economides, 2008). El recorrido histórico de la evaluación Web como práctica académica puede clasificarse de forma general en dos grandes corrientes: primero cualitativa y posteriormente cuantitativa, aunque en la actualidad muchos investigadores están integrando ambos enfoques (Law et.al., 2010). Sin embargo, es difícil unir a todos los instrumentos para formar un único estándar para la evaluación de un sitio Web (Morrison et al., 2004). Hay varias clasificaciones que categorizan la evaluación de sitios Web, a partir de Law et al. (2010) se establecen dos categorías principales:

- Modelos que adoptaron y/o modificaron instrumentos de evaluación ya existentes.

- Métodos innovadores, que desarrollan nuevos modelos de evaluación.

\section{Cuadro 2 \\ VENTAJAS E INCONVENIENTES \\ EN LA EVALUACIÓN DE LOS SITIOS WEB}

\begin{tabular}{|l|l|l|}
\hline \multicolumn{1}{|c|}{ Métodos adaptados } & \multicolumn{1}{|c|}{ Ventajas } & \multicolumn{1}{c|}{ Inconvenientes } \\
\hline Recuento & $\begin{array}{l}\text { Identifica determinadas } \\
\text { características. }\end{array}$ & No refleja la facilidad de uso. \\
\hline Opinión usuarios & $\begin{array}{l}\text { Evalúan la percepción y } \\
\text { satisfacción de los usuarios. }\end{array}$ & $\begin{array}{l}\text { No ofrece el rendimiento de una } \\
\text { Web en términos numéricos. }\end{array}$ \\
\hline Automático & $\begin{array}{l}\text { Mide el rendimiento técnico } \\
\text { de ciertas características. }\end{array}$ & $\begin{array}{l}\text { No hay implicación de los } \\
\text { usuarios. }\end{array}$ \\
\hline Cálculo numérico & $\begin{array}{l}\text { Mide el rendimiento con } \\
\text { marcadores numéricos. }\end{array}$ & Proceso complejo. \\
\hline Método combinado & Se basa en los anteriores. & Puede llegar a ser muy sofisticado. \\
\hline
\end{tabular}

Fuente: Elaboración propia a partir de Law et al. (2010).

\subsection{Modelo $e M I C A$}

Burgess y Cooper (1999) desarrollaron el modelo denominado MICA (Model of Internet Commerce Adoption), que consiste en posicionar el desarrollo de un sitio Web en función de tres etapas: Promoción, primera fase que recoge informaciones acerca de la empresa; la segunda etapa es Provisión que indica el nivel de interactividad; y la tercera es Procesamiento que muestra el nivel de transacciones online. Posteriormente ampliaron las funcionalidades contenidas en cada etapa y se renombró el modelo como eMICA (extended MICA) (Burgess y Cooper, 2000).

La base del modelo para el presente estudio es la adaptación realizada por García y Escalera (2008) que analizaron en el año 2007 el uso de Internet que hacían las estaciones 
de esquí y montaña en España y Andorra. Este trabajo es un paso más en esta línea de investigación, al evaluar longitudinalmente el avance de los sitios Web de las estaciones de esquí y montaña, ampliando la muestra a las estaciones localizadas en el Pirineo de Francia. Se reduce el número de variables de 38 a 28 con el objeto de hacer un modelo más ajustado y operativo, y se incluye alguna utilidad reciente como por ejemplo las redes sociales.

En esta investigación se ha seleccionado la metodología de Recuento por ser consistente con los objetivos del trabajo y ser ampliamente utilizada en la literatura previa. El método de contabilización de elementos se utiliza para valorar el desempeño de un sitio Web o su riqueza (Law et al., 2010). Cuenta con algunas limitaciones, entre otras Schmidt (2006) señala que tienden a reducir el nivel de complejidad de las investigaciones; sin embargo, la lista de variables o indicadores previamente definidos facilita la comparación objetiva de los sitios Web en el tiempo y en diferentes regiones del mundo (Yeung y Lu, 2004). Los sitios Web en Internet se van moviendo de una posición estática a una más dinámica, incorporando información útil y funcionalidad (Timmers, 1998).

\section{Cuadro 3}

THE EXTENDED MODEL OF INTERNET COMMERCE ADOPTION. EL MODELO eMICA

\begin{tabular}{|c|c|c|}
\hline eMICA & & Ejemplos de funcionalidad \\
\hline \multirow{3}{*}{ Escalón 1} & Promoción & \\
\hline & Capa 1 Información básica & $\begin{array}{l}\text { Denominación, dirección física y detalles de } \\
\text { contacto, área de actividad }\end{array}$ \\
\hline & Capa 2 Información rica & Informe anual, e-mail, actividades de la compañía \\
\hline \multirow{4}{*}{ Escalón 2} & Provisión & \\
\hline & Capa 1 Interactividad baja & $\begin{array}{l}\text { Catálogo básico del producto, links a otras } \\
\text { informaciones, formulario online }\end{array}$ \\
\hline & Capa 2 Interactividad media & $\begin{array}{l}\text { Catálogos completos del producto, soporte al } \\
\text { usuario (FAQs, mapa sitio Web, etc.), información } \\
\text { del sector }\end{array}$ \\
\hline & Capa 3 Interactividad alta & $\begin{array}{l}\text { Chat, foros de discusión, multimedia, newsletters o } \\
\text { noticias por e-mail }\end{array}$ \\
\hline Escalón 3 & Proceso & Transacciones seguras, interacción con servidores \\
\hline
\end{tabular}

Fuente: elaboración propia a partir de Burgess y Cooper (2000).

\section{LA INVESTIGACIÓN}

Se analizan 78 sitios Web: 34 de España, 2 de Andorra y 42 de Francia; que se corresponden con el total de la estaciones de esquí y montaña asociadas en ATUDEM, los dominios esquiables de Andorra, integrados en SKI ANDORRA, y las estaciones de esquí y montaña de los Pirineos en Francia, agrupados en la Confederación Pirenaica de Turismo, 
LES PYRÉNÉES. Son estaciones de esquí situadas en la misma área de influencia, principalmente el Pirineo. Se analiza la evolución desde la temporada 2009-10 a la temporada 2013-14. Los datos se corresponden a las observaciones realizadas entre los días 12 y 15 de marzo de 2010; y entre el 01 y 04 de marzo de 2014. Hay algunas estaciones de esquí que comparten sitio Web tanto en la modalidad alpina como nórdica: Candanchú, Mijanes - Donezan, La Pierre - Saint Martin, Cauterets, Font-Romeu Pyrénées 2000, Grand Tourmalet y Hautacam.

Para adaptar el modelo eMICA, se ha tenido en cuenta las características de una estación de esquí y las particularidades ya reseñadas del segmento de turismo de nieve y montaña, desde el punto de vista de un usuario. Kotler et al. (2004) señalan que un portal de destinos turísticos debería ofrecer información sobre algunos aspectos esenciales: cómo llegar al destino, qué actividades se pueden realizar o dónde hospedarse. A partir de CMTNM (2010) citamos algunas funciones que deben tener los sitios Web en las estaciones de esquí y montaña:

- Facilitar información.

- Promocionar la información, por ejemplo en redes sociales como Facebook o Twitter.

- Interactuar con los clientes y los prescriptores.

- Facilitar las ventas de estancia, alojamiento o cualquier tipo de producto.

En la selección de las variables hemos determinado las siguientes premisas:

- Hay unas variables básicas y de obligado cumplimiento para poder consolidar nivel y capa (aparecen en negrita en los siguientes cuadros).

- Se pasará de nivel siempre que el sitio Web contenga las variables correspondientes al último nivel o capa.

La escala es dicotómica (SI / NO) para todos las variables; la presencia o ausencia de determinadas características supone una menor subjetividad que evaluar otros ítems como accesibilidad al sitio Web, variedad de información o colores. En el caso del indicador Idioma, se corresponde con SI cuando el sitio Web presenta la información en el idioma inglés, además del propio del país. El inglés es seleccionado por su predominio como idioma en la red (Fundación-Orange, 2007). Las personas prefieren utilizar su propio idioma, así es necesario estar preparados para comunicar en varios idiomas, tanto en el sitio Web como por e-mail (Ho, 2002).

\subsection{Primer nivel: Promoción}

En la adaptación del modelo $e M I C A$, en este primer nivel, Internet se convierte en un medio de información, con escaso nivel de funcionalidad pero información elemental en una estación de esquí y montaña. Contiene elementos de información como: datos de contacto, localización o medios de transporte para llegar al destino. Presenta dos capas:

En la capa 1, se exige tener un mínimo de tres variables de las cinco propuestas. 


\section{Cuadro 4 \\ VARIABLES DEL PRIMER NIVEL: CAPA 1}

\section{Nivel 1: Promoción (Información)}

Capa 1: Información Básica

1 Datos de contacto: Denominación, dirección, teléfono, fax, otros

2 Fecha y Hora de actualización

3 Estado de la estación: Abierta / Cerrada

4 Accesos a la estación: Abiertos / Cerrados / Cadenas

5 Imágenes

Fuente: elaboración propia a partir del modelo eMICA (Burgess y Cooper, 2000).

Un sitio Web se encontrará en esta capa siempre que reúna al menos los tres primeros indicadores y pasará a la siguiente cuando cumpla los cinco.

En la capa 2, también se necesita tener un mínimo de tres variables de las cinco propuestas. Una OMD ganadora debe proporcionar mejor información que sus competidores (OMT, 1999). En la capa y nivel que nos encontramos, hay que ofrecer un mayor nivel de detalle de los productos y servicios. La empresa utiliza Internet como un medio de promoción de sus productos y servicios al mercado, como una comunicación uno para muchos (Doolin et al., 2002, Chaffey et al., 2003).

\section{Cuadro 5}

VARIABLES DEL PRIMER NIVEL: CAPA 2

\begin{aligned} & \hline Nivel 1: Promoción (Información) \\ & \hline 6 Capa 2: Información Abundante \\ & \hline 7 Informe de pistas: Perfil, remontes, espesores, cotas, otros \\ & \hline 8 Cómo llegar a la estación (destino) \\ & \hline 9 Parte de meteorología: Actual / Previsión \\ & \hline 10 Idiomas (otros) \\ & \hline\end{aligned}

Fuente: elaboración propia a partir del modelo eMICA (Burgess y Cooper, 2000).

\subsection{Segundo nivel: Provisión}

Recoge información dinámica de la estación de esquí y montaña. El sitio presenta un grado más de funcionalidad, e información más detallada con contenidos multimedia de la oferta de la propia estación y de su entorno: historia, fiestas, gastronomía, patrimonio, rutas, agenda, o enlaces con otras formas de turismo. Un sitio Web debe proporcionar 
información actualizada a clientes sobre los productos, con contenido interactivo y personalizado (Teo y Pian, 2003). El objetivo es dar a conocer mejor el destino y mostrar experiencias previas al consumo.

En la capa 1 de este nivel requiere un mínimo de tres variables de las seis propuestas.

\section{Cuadro 6}

VARIABLES DEL SEGUNDO NIVEL: CAPA 1

\begin{tabular}{ll}
\hline & Nivel 2: Provisión (Información dinámica) \\
\hline & Capa 1: Nivel bajo de interactividad \\
\hline 11 & Tarifas forfaits y abonos temporada \\
\hline 12 & Plano de pistas \\
\hline 13 & Enlaces información (interna / externa): Alojamientos, restaurantes, otros \\
\hline 14 & Invierno - Verano (enlaces) \\
\hline 15 & Calendario temporada completo / Agenda \\
\hline 16 & Información sobre seguridad \\
\hline
\end{tabular}

Fuente: elaboración propia a partir del modelo eMICA (Burgess y Cooper, 2000).

En las utilidades de un sitio Web (Pan et al., 2007) establecen una división, por un lado los elementos que facilitan la navegación, búsqueda y localización de información entre los contenidos como el buscador o mapa Web; por otro, los que permiten la comunicación entre usuarios y éstos con la organización, como redes sociales, blogs o foros, que una parte de los destinos turísticos de relevancia se han apresurado a incorporar.

En la capa 2 se necesita tener un mínimo de tres variables de las cinco propuestas.

Cuadro 7

VARIABLES DEL SEGUNDO NIVEL: CAPA 2

Nivel 2: Provisión (Información dinámica)

Capa 2: Nivel medio de interactividad

17 Mapa Web

18 Web Cam

19 Posibilidad de hacer reserva o enlace: alojamiento y/o forfait

20 Newsletter: envío de noticias por e-mail, boletines electrónicos, FAQ

21 Política de privacidad o aviso legal

Fuente: elaboración propia a partir del modelo eMICA (Burgess y Cooper, 2000). 
En la capa 3 se requiere un mínimo de tres variables de las cinco propuestas. En esta última capa del segundo nivel se registran aquellos sitios que permitan cerrar el proceso de compra. Los destinos turísticos pueden ser ganadores al comercializar su producto directamente por Internet, aprovechando su conocimiento especializado (CEOMT, 1999).

\section{Cuadro 8}

VARIABLES DEL SEGUNDO NIVEL: CAPA 3

\begin{aligned} & \hline Nivel 2: Provisión (Información dinámica) \\ & \hline 22 Capa 3: Nivel alto de interactividad \\ & \hline 23 Zona Clientes: Socios / Foros / Chats / Blogs \\ & \hline 24 Aplicaciones multimedia: descarga de folletos y/o materiales y/o fotos \\ & \hline 25 Plano de pistas interactivo \\ & \hline 26 Buscador (por palabras, etc) \\ & \hline\end{aligned}

Fuente: elaboración propia a partir del modelo eMICA (Burgess y Cooper, 2000).

\subsection{Proceso}

En el tercer nivel, Internet se convierte en un potente medio de comercio electrónico. Los compradores y vendedores pueden llevar a cabo transacciones con los productos y servicios ofrecidos, más allá de una herramienta de comunicación e información. Huizingh (2000) señala que las transacciones son parte del contenido, y no una categoría en separado.

\section{Cuadro 9 \\ VARIABLES DEL TERCER NIVEL}

\begin{tabular}{ll}
\hline \multicolumn{2}{c}{ Nivel 3: Proceso (Madurez Funcional) } \\
\hline 27 & Transacción online segura (en los procesos de compra posibles) \\
\hline 28 & Normas y Condiciones: cancelación de reserva, etc. \\
\hline
\end{tabular}

Fuente: elaboración propia a partir del modelo eMICA (Burgess y Cooper, 2000).

\section{LOS RESULTADOS}

De los sitios Web analizados, 34 de España, 2 de Andorra y 42 de Francia, 78 en total entre las temporadas 2009-10 y 2013-14, más de un 90\% de los sitios alcanza alguno de los niveles. Con un incremento del $3,85 \%$ entre las dos temporadas. 


\section{Figura 2 \\ EVOLUCIÓN POR NIVEL SITIOS WEB. \\ TEMPORADAS 2009-10 Y 2013-14}

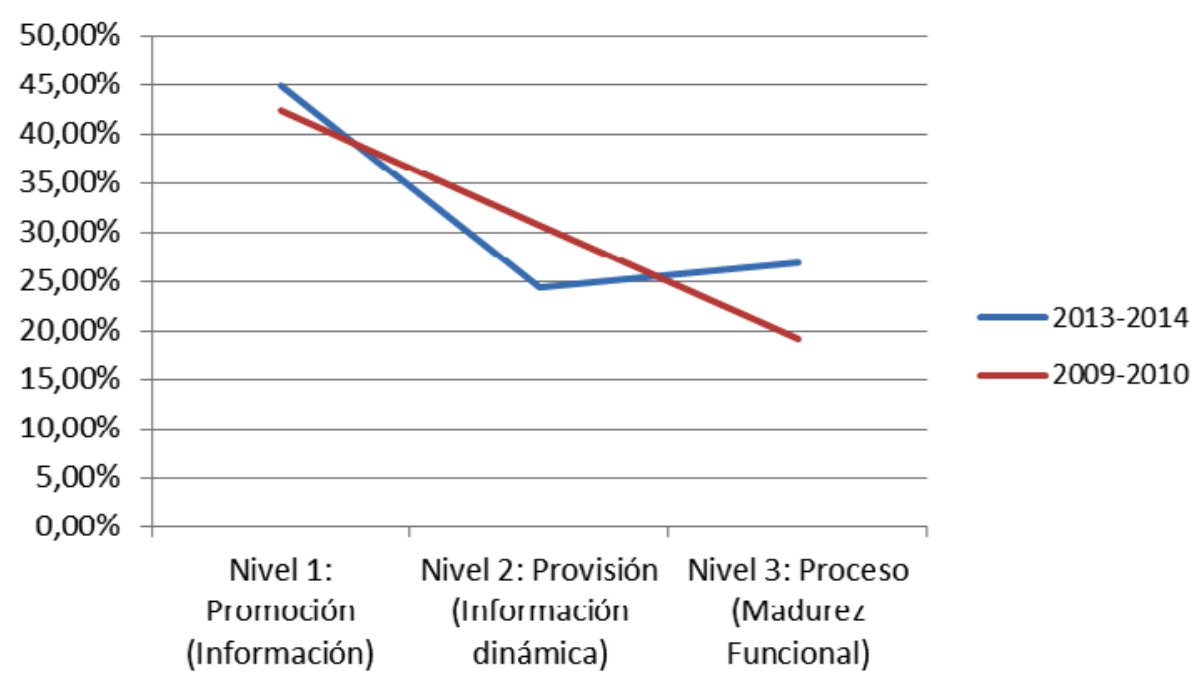

Fuente: elaboración propia.

Según el modelo adaptado eMICA, el grado de madurez funcional ha variado entre las temporadas 2009-10 y 2013-14, sobre todo en el Nivel 2 de Provisión con una reducción del 6,41\% y en el Nivel 3 de Proceso con un incremento del 7,69\% del total de los sitios Web analizados. En el Nivel 1 de Promoción, el escalón más básico de un sitio Web, no se producen prácticamente cambios.

\subsection{Distribución de los resultados por Nivel y Capa}

En este punto analizamos el grado de cumplimiento de los diferentes indicadores. En los cuadros van en negrita aquellas variables consideras obligatorias para consolidar la capa correspondiente según modelo adaptado. Nos detendremos, a la vista de los resultados, en aquellos que resulten especialmente llamativos.

En el detalle por Nivel y Capa, se observan alguno de los cambios producidos. En la temporada 2013-14, el Nivel 1 de Promoción es alcanzado por el 44\% del total, con un incremento del 2,56\%, hasta un total de 35 sitios Web. En el Nivel 2 se sitúan 19 sitios, un $24 \%$, de los cuales más de la mitad se ubican en el nivel bajo de interactividad. La variación más significativa se da en el Nivel 3, alcanzado por 21 sitios Web que representan el $26 \%$.

Aunque hay una evolución de los sitios Web hacia un mayor grado de interactividad con el usuario, también es cierto que prácticamente la mitad siguen ubicados en el Nivel 1 de información. En este nivel, casi todas las variables tienen un grado de cumplimiento por 
encima del 90\% en la temporada 2013-14, salvo la variable Idiomas que alcanza un 57\%, 45 de los 78 sitios Web analizados, y con apenas cambios desde la temporada 2009-10, tan sólo un sitio más. Dato sorprendente por la importancia de comunicar en el idioma del usuario o demandante, sobre todo cuando muchas de las estaciones de esquí y montaña se sitúan en entornos de otros países, en clara posición de competencia interna y externa por atraer turistas.

Cuadro 10

DISTRIBUCIÓN TOTAL DE LOS SITIOS WEB. TEMPORADAS 2009-10 Y 2013-14

\begin{tabular}{lcccc}
\hline & $\mathbf{2 0 1 3 - 1 4}$ & $\%$ & $\mathbf{2 0 0 9}-10$ & $\%$ \\
\hline Nivel 1: Promoción (Información) & 35 & $\mathbf{4 4 , 8 7 \%}$ & $\mathbf{3 3}$ & $\mathbf{4 2 , 3 1 \%}$ \\
\hline Capa 1: Información Básica & $\mathbf{6}$ & $\mathbf{7 , 6 9 \%}$ & $\mathbf{5}$ & $\mathbf{6 , 4 1 \%}$ \\
\hline Capa 2: Información Abundante & 29 & $\mathbf{3 7 , 1 8 \%}$ & $\mathbf{2 8}$ & $\mathbf{3 5 , 9 0 \%}$ \\
\hline Nivel 2: Provisión (Información dinámica) & 19 & $\mathbf{2 4 , 3 6 \%}$ & $\mathbf{2 4}$ & $\mathbf{3 0 , 7 7 \%}$ \\
\hline Capa 1: Nivel bajo de interactividad & 12 & $\mathbf{1 5 , 3 8 \%}$ & $\mathbf{1 8}$ & $\mathbf{2 3 , 0 8 \%}$ \\
\hline Capa 2:: Nivel medio de interactividad & $\mathbf{2}$ & $\mathbf{2 , 5 6 \%}$ & $\mathbf{2}$ & $\mathbf{2 , 5 6 \%}$ \\
\hline Capa 3: Nivel alto de interactividad & $\mathbf{5}$ & $\mathbf{6 , 4 1 \%}$ & $\mathbf{4}$ & $\mathbf{5 , 1 3 \%}$ \\
\hline Nivel 3: Proceso (Madurez Funcional) & $\mathbf{2 1}$ & $\mathbf{2 6 , 9 2 \%}$ & $\mathbf{1 5}$ & $\mathbf{1 9 , 2 3 \%}$ \\
\hline \multicolumn{1}{c}{ TOTAL } & $\mathbf{7 5}$ & $\mathbf{9 6 , 1 5 \%}$ & $\mathbf{7 2}$ & $\mathbf{9 2 , 3 1 \%}$ \\
\hline
\end{tabular}

Fuente: Elaboración propia.

\section{Cuadro 11}

COMPARATIVO DISTRIBUCIÓN RESULTADOS POR VARIABLES EN EL NIVEL 1. TEMPORADAS 2009-10 Y 2013-14

\begin{tabular}{llcccc}
\hline & $\mathbf{2 0 1 3 - 1 4}$ & $\mathbf{\%}$ & $\mathbf{2 0 0 9 - 1 0}$ & $\boldsymbol{\%}$ \\
\hline NIVEL 1: Promoción & $\mathbf{3 5}$ & $\mathbf{4 4 , 8 7 \%}$ & $\mathbf{3 3}$ & $\mathbf{4 2 , 3 1 \%}$ \\
\hline Capa 1: Información básica & $\mathbf{6}$ & $\mathbf{7 , 6 9 \%}$ & $\mathbf{5}$ & $\mathbf{6 , 4 1 \%}$ \\
\hline $\mathbf{1}$ & Datos contacto: dirección, otros & $\mathbf{7 8}$ & $\mathbf{1 0 0 , 0 0 \%}$ & $\mathbf{7 7}$ & $\mathbf{9 8 , 7 2 \%}$ \\
\hline $\mathbf{2}$ & Fecha y hora de actualización & $\mathbf{7 5}$ & $\mathbf{9 6 , 1 5 \%}$ & $\mathbf{7 4}$ & $\mathbf{9 4 , 8 7 \%}$ \\
\hline $\mathbf{3}$ & Estado de la estación: Abierta / Cerrada & $\mathbf{7 5}$ & $\mathbf{9 6 , 1 5 \%}$ & $\mathbf{7 2}$ & $\mathbf{9 2 , 3 1 \%}$ \\
\hline 4 Accesos a la estación: Abiertos / Cerrados & 75 & $96,15 \%$ & 72 & $92,31 \%$ \\
\hline 5 & Imágenes del destino & 78 & $100,00 \%$ & 78 & $100,00 \%$ \\
\hline & Capa 2: Información rica & $\mathbf{2 9}$ & $\mathbf{3 7 , 1 8 \%}$ & $\mathbf{2 8}$ & $\mathbf{3 5 , 9 0 \%}$ \\
\hline $\mathbf{6}$ & E-mail y/o Formulario & $\mathbf{7 8}$ & $\mathbf{1 0 0 , 0 0 \%}$ & $\mathbf{7 7}$ & $\mathbf{9 8 , 7 2 \%}$ \\
\hline $\mathbf{7}$ & Informe de pistas: perfil, remontes, otros & $\mathbf{7 1}$ & $\mathbf{9 1 , 0 3 \%}$ & $\mathbf{7 2}$ & $\mathbf{9 2 , 3 1 \%}$ \\
\hline $\mathbf{8}$ & Cómo llegar a la estación (destino) & $\mathbf{7 8}$ & $\mathbf{1 0 0 , 0 0 \%}$ & $\mathbf{7 7}$ & $\mathbf{9 8 , 7 2 \%}$ \\
\hline 9 Parte de meteorología: Actual / Previsión & 77 & $98,72 \%$ & 75 & $96,15 \%$ \\
\hline 10 & Idiomas (otros) & 45 & $57,69 \%$ & 44 & $56,41 \%$ \\
\hline
\end{tabular}

Fuente: Elaboración propia. 
El Nivel 2 de Provisión muestra el grado de interactividad. El usuario puede participar de manera activa en la gestación del servicio. Los resultados aquí no son tan homogéneos como en el nivel anterior. El 15\% de los sitios se sitúan en la parte baja de interactividad en la temporada 2013-14, que son 6 sitios menos que en la temporada 2009-10. Casi todos los sitios cumplen con las variables de obligado cumplimiento: Tarifas de precios, Plano de pistas y Enlaces de información tanto internos como externos del entorno. El resto de variables han mejorado respecto a la temporada 2009-10: Información de verano e invierno e Información sobre seguridad crecen más de un 5\%; mientras que la variable Calendario / Agenda se mantiene en el $80 \%$.

En la parte media de interactividad hay dos sitios Web, con un comportamiento positivo en casi todas las variables en la temporada 2013-14: Mapa Web está presente en 38 de los 78 sitios Web; el servicio de Webcam, que permite mostrar en tiempo real la situación climatológica de la estación, es ofrecido por el $82 \%$ y la opción de Realizar reserva o un enlace que lo permita alcanza el $89 \%$. Las variables Envío noticias por email y Política de privacidad, que completan esta Capa 2, superan el $80 \%$.

En la Capa 3 hay una mejora en las variables de obligado cumplimiento para consolidar, son las que mejor comportamiento experimentan en esta parte alta de interactividad: Proceso de compra completo es alcanzado por el 69\%, con un incremento del $14 \%$ respecto a la temporada 2009-10; Zona de clientes/socios llega al $91 \%$ y pasa de 41 a 71 sitios Web, es la variable que más ha crecido en estas cinco temporadas, signo inequívoco de la importancia de las redes sociales y la presencia del turista en la red, y Descarga de folletos o imágenes es posible en la totalidad de sitios Web en la temporada 2013-14. Las otras dos herramientas Plano de pistas interactivo y Buscador son localizadas en más de la mitad de los sitios.

Cuadro 12

COMPARATIVO DISTRIBUCIÓN RESULTADOS POR VARIABLES EN EL NIVEL 2. TEMPORADAS 2009-10 Y 2013-14

\begin{tabular}{llcccc}
\hline & $\mathbf{2 0 1 3 - 1 4}$ & $\boldsymbol{\%}$ & $\mathbf{2 0 0 9 - 1 0}$ & $\boldsymbol{\%}$ \\
\hline & NIVEL 2: Provisión & $\mathbf{1 9}$ & $\mathbf{2 4 , 3 6 \%}$ & $\mathbf{2 4}$ & $\mathbf{3 0 , 7 7 \%}$ \\
\hline & Capa 1: Nivel bajo de interactividad & $\mathbf{1 2}$ & $\mathbf{1 5 , 3 8 \%}$ & $\mathbf{1 8}$ & $\mathbf{2 3 , 0 8 \%}$ \\
\hline $\mathbf{1 1}$ & Tarifas forfaits y abonos temporada & $\mathbf{7 8}$ & $\mathbf{1 0 0 , 0 0 \%}$ & $\mathbf{7 7}$ & $\mathbf{9 8 , 7 2 \%}$ \\
\hline $\mathbf{1 2}$ & Plano de pistas & $\mathbf{7 6}$ & $\mathbf{9 7 , 4 4 \%}$ & $\mathbf{7 4}$ & $\mathbf{9 4 , 8 7 \%}$ \\
\hline $\mathbf{1 3}$ & Enlaces información (interna / externa) & $\mathbf{7 7}$ & $\mathbf{9 8 , 7 2 \%}$ & $\mathbf{7 5}$ & $\mathbf{9 6 , 1 5 \%}$ \\
\hline 14 & Invierno - Verano (enlaces) & 74 & $94,87 \%$ & 70 & $89,74 \%$ \\
\hline 15 & Calendario temporada completo / Agenda & 62 & $79,49 \%$ & 64 & $82,05 \%$ \\
\hline 16 & Información sobre seguridad & 58 & $74,36 \%$ & 53 & $67,95 \%$ \\
\hline & Capa 2: Nivel medio de interactividad & $\mathbf{2}$ & $\mathbf{2 , 5 6 \%}$ & $\mathbf{2}$ & $\mathbf{2 , 5 6 \%}$ \\
\hline $\mathbf{1 7}$ & Mapa Web & $\mathbf{3 8}$ & $\mathbf{4 8 , 7 2 \%}$ & $\mathbf{4 0}$ & $\mathbf{5 1 , 2 8 \%}$ \\
\hline $\mathbf{1 8}$ & Web Cam & $\mathbf{6 4}$ & $\mathbf{8 2 , 0 5 \%}$ & $\mathbf{5 8}$ & $\mathbf{7 4 , 3 6 \%}$ \\
\hline $\mathbf{1 9}$ Posibilidad de hacer reserva o enlace & $\mathbf{7 0}$ & $\mathbf{8 9 , 7 4 \%}$ & $\mathbf{6 4}$ & $\mathbf{8 2 , 0 5 \%}$ \\
\hline
\end{tabular}




\begin{tabular}{llcccc}
\hline 20 & Newsletter: envío de noticias por e-mail, otros & 63 & $80,77 \%$ & 58 & $74,36 \%$ \\
\hline 21 & Política de privacidad o aviso legal & 66 & $84,62 \%$ & 62 & $79,49 \%$ \\
\hline Capa 3: Nivel alto de interactividad & $\mathbf{5}$ & $\mathbf{6 , 4 1 \%}$ & $\mathbf{4}$ & $\mathbf{5 , 1 3 \%}$ \\
\hline $\mathbf{2 2}$ & $\begin{array}{l}\text { Proceso compra completo alojamiento y/o } \\
\text { forfait }\end{array}$ & $\mathbf{5 4}$ & $\mathbf{6 9 , 2 3 \%}$ & $\mathbf{4 3}$ & $\mathbf{5 5 , 1 3 \%}$ \\
\hline $\mathbf{2 3}$ Zona Clientes: Socios / Foros / Chats / Blogs & $\mathbf{7 1}$ & $\mathbf{9 1 , 0 3 \%}$ & $\mathbf{4 1}$ & $\mathbf{5 2 , 5 6 \%}$ \\
\hline $\mathbf{2 4}$ & $\begin{array}{l}\text { Aplicaciones multimedia: descarga folletos, } \\
\text { otros }\end{array}$ & $\mathbf{7 8}$ & $\mathbf{1 0 0 , 0 0 \%}$ & $\mathbf{6 5}$ & $\mathbf{8 3 , 3 3 \%}$ \\
\hline 25 Plano de pistas interactivo & 46 & $58,97 \%$ & 50 & $64,10 \%$ \\
\hline 26 Buscador (por palabras, etc) & 40 & $51,28 \%$ & 28 & $35,90 \%$ \\
\hline
\end{tabular}

Fuente: elaboración propia.

En el Nivel 3, de Proceso, también se incrementa la capacidad de los sitios Web para realizar una Transacción online segura, se pasa de 42 a 52 sitios Web, y el $73 \%$ tienen establecidas Normas y condiciones de cancelación de reserva en la temporada 2013-14.

\section{Cuadro 13 \\ COMPARATIVO DISTRIBUCIÓN RESULTADOS POR VARIABLES EN EL NIVEL 3. TEMPORADAS 2009-10 Y 2013-14}

\begin{tabular}{llrrrr}
\hline & & $\mathbf{2 0 1 3 - 1 4}$ & \multicolumn{2}{c}{$\mathbf{2 0 0 9 - 1 0}$} & $\boldsymbol{\%}$ \\
\hline & NIVEL 3: Proceso & $\mathbf{2 1}$ & $\mathbf{2 6 , 9 2 \%}$ & $\mathbf{1 5}$ & $\mathbf{1 9 , 2 3 \%}$ \\
\hline 27 & Transacción online segura & $\mathbf{5 2}$ & $\mathbf{6 6 , 6 7 \%}$ & $\mathbf{4 2}$ & $\mathbf{5 3 , 8 5 \%}$ \\
\hline 28 & Normas y condiciones: cancelación reserva, etc. & 57 & $73,08 \%$ & 44 & $56,41 \%$ \\
\hline
\end{tabular}

Fuente: elaboración propia.

\subsection{Distribución de los resultados por variable}

Entre las temporadas 2009-10 y 2013-14 se han duplicado las variables que los sitios Web han conseguido respecto a las que se han perdido. El resultado neto por número de variables es positivo entre las dos temporadas.

El 69\% de las variables obligatorias (16) para consolidar Capa y Nivel, son alcanzadas por más del $90 \%$ de los sitios. Casi la totalidad de las variables, salvo Mapa Web son conseguidas por el $50 \%$ o más de sitios Web.

Si ordenamos las variables por grado de cumplimiento, la variable que más se ha incrementado es Zona de Clientes que ha sumado 30 sitios Web. Esta incorporación de las redes sociales es un hecho diferenciador entre las dos temporadas. Las nuevas tecnologías han facilitado el intercambio de información sobre productos entre consumidores (Stephen y Lehmann, 2009), estos pueden interactuar unos con otros a través de e-mail, blogs, foros, comunidades virtuales, páginas de opinión y redes sociales (Goldsmith, 2006). Las siguientes son: Buscador, Normas sobre cancelación de reserva y variables que permiten realizar el proceso de compra completo como Transacción online segura y Proceso de compra completo. 


\subsection{Distribución de los resultados por sitio Web}

Mejora el grado de funcionalidad con el usuario en más de la mitad de los sitios Web, en el $52 \%$ de los sitios; el $19 \%$ pierde alguna de las variables mientras que el $28 \%$ no experimentan variación.

\section{Cuadro 14}

BALANCE DE LOS SITIOS WEB ENTRE LAS TEMPORADAS 2009-10 Y 2013-14

\begin{tabular}{lcc}
\hline Balance & Cantidad & $\%$ \\
\hline Positivo & 41 & $\mathbf{5 2 , 5 6 \%}$ \\
\hline Negativo & 15 & $19,23 \%$ \\
\hline Sin variación & 22 & $\mathbf{2 8 , 2 1 \%}$ \\
\hline
\end{tabular}

Fuente: elaboración propia.

Teniendo en cuenta los resultados de las observaciones realizadas en los sitios Web de las estaciones de esquí y montaña de España, Andorra y Francia Pirineos, y atendiendo al modelo de distribución adaptado por etapas y capas $e M I C A$, el balance global es ligeramente positivo, en la medida que en la temporada 2013-14 prácticamente la mitad de los sitios Web siguen localizados en el Nivel 1 de Promoción, similar a la temporada 2009-10.

\section{CONCLUSIONES}

España es líder mundial en turismo, esta posición de privilegio hace imprescindible estar más alerta ante los retos que tiene el sector, que pasa por ser más competitivo y diversificar la oferta. En este trabajo, además de resaltar la importancia creciente del turismo de nieve y montaña, el objetivo básico ha sido desarrollar y aplicar longitudinalmente un modelo exploratorio que caracterice los sitios Web de las estaciones de esquí y montaña como destino turístico.

La metodología utilizada y adaptada ha sido eMICA (Burgess y Cooper, 2000), que recoge las tres etapas por las que gradualmente un sitio Web transcurre hasta conseguir la madurez funcional: información, provisión y proceso; y que recoge las tres dimensiones vinculadas a Internet: información, comunicación y transacción (Mañá y Escobar, 2005). Las 28 variables seleccionadas y evaluadas fueron distribuidas en estos tres niveles, dotando al instrumento de un notable grado de manejabilidad y simplicidad. La muestra alcanzó a 78 sitios Web, que se corresponden con el total de estaciones de esquí y montaña de España, Andorra y los Pirineos de Francia. Destinos que reúnen características homogéneas y comparten en su mayor parte ubicación geográfica, lo que posibilita la comparabilidad de los datos.

Los resultados pertenecen a las temporadas 2009-10 y 2013-14; y aunque hay una pequeña evolución positiva entre ambas temporadas, los sitios Web siguen mostrando un bajo grado de madurez funcional, situándose principalmente en los dos primeros niveles del modelo. El Nivel 1 (Información) lo alcanzan 35 sitios, en el Nivel 2 (Provisión) consolidan 19; hay tres sitios que no afianzan nivel. 
En el análisis individual por variables, el balance es más positivo, especialmente en aquellas relacionadas con la interactividad y el proceso de compra; destaca el crecimiento experimentado por la variable Zona de clientes que ha pasado a estar presente en 71 sitios Web, 30 más que en el temporada 2009-10. Un primer paso que no debe hacer bajar la guardia; (Hays et al., 2012) alertan que la interacción en las redes sociales es todavía escasa. Para desarrollar con éxito las estrategias de medios sociales en el futuro, las OMDs deben reconocer el alcance e impacto que pueden tener pues no podemos ignorar estas tecnologías y los cambios que están causando en el comportamiento de los viajeros (Wang et al. 2002). En la parte negativa el escaso avance de la utilidad Idioma, un sitio más respecto a la temporada 2009-10; la comunicación es efectiva si se produce en el idioma del usuario.

Entendemos que los resultados del presente estudio revelan la necesidad de las Estaciones de Esquí y Montaña de reforzar los recursos empleados en la red y no infrautilizar las oportunidades inherentes a las TICs. El propósito de este trabajo, no ha sido buscar deficiencias sino detectar las oportunidades de mejora, que orienten a las organizaciones y personas que gestionan los sitios Web, a ser más eficaces y competitivos en la red y por ende, en sus estrategias. El potencial del entorno Web sigue desaprovechado mostrando que el uso efectivo de Internet en la promoción continua siendo un reto para las organizaciones turísticas (Zach et al., 2007).

La continuidad de este trabajo puede alcanzar una muestra más extensa, que incluya más regiones de países europeos y no europeos; ampliando el enfoque de análisis y validando el modelo propuesto, relacionando por ejemplo el desarrollo de los sitios Web con el tamaño de las estaciones de Esquí, en línea con otras investigaciones que han descubierto que el uso de Internet y de la Web en particular, está relacionado, entre otros factores, con el tamaño de las empresas (Burke, 2005).

\section{BIBLIOGRAFÍA}

ABEGG, B., AGRAWALA, S., CRICK, F. y MONTFALCON, A. (2007): «Effets des changements climatiques et adaptation dans le tourisme d'hiver». En Agrawala, S. (Dir.), Changements climatiques dans les Alpes européennes. Adapter le tourisme d'hiver et la gestion des risques naturels. Paris: Editions OCDE.

AGUILÓ, E. y ALEGRE J. (2004): «La madurez de los destinos turísticos de sol y playa. El caso de las islas baleares», en Papeles de Economía Española, 102, pp. 250-270.

ATUDEM. Asociación Turística de Estaciones de Esquí y Montaña (2014): Consulta 22/02/2014 en http://www.atudem.org/

ATUDEM. Asociación Turística de Estaciones de Esquí y Montaña (2015): Consulta 26/01/2015 en http://www.atudem.org/

BIGNÉ, J.E., FONT, X. y ANDREU, L. (2000): Marketing de los destinos turísticos. Análisis y estrategias de desarrollo. Madrid: Ed. ESIC.

AYORA, A. (2008): Gestión del riesgo en montaña y actividades al aire libre. Madrid: Ed. Desnivel.

BOE. Boletín Oficial de las Cortes Núm 791 (2007): Informe de la ponencia, constituida en el seno de la comisión de industria, turismo y comercio, para el estudio del fenómeno de la desestacionalización en el sector turístico y para la elaboración de una propuesta 
normativa que garantice el uso racional de las estaciones de esquí, en la parte relativa al estudio de la desestacionalización en el sector turístico; así como aprobación de dicho informe por la comisión en su sesión del día 2 de octubre de 2007 (543/000007).

BUHALIS, D. (2000): «Marketing the competitive destination of the future», en Tourism Management, 21 (1), pp. 97-116.

BUHALIS, D. y LAW, R. (2008): «Progress in information technology and tourism management: 20 years on and 10 years after the Internet: the state of etourism research», en Tourism management, 29 (4), pp. 609-623.

BURGESS, L. y COOPER, J. (1999): «A model for classification of business adoption of Internet commerce solutions», en Actas del Global networked organizations, Twelth International Bled Electronic Commerce Conference. Bled, Slovenia.

BURGESS, L. y COOPER, J., (2000): «Extending the viability of mica as a metric for explaining the process of business adoption of Internet commerce», en The International Conference on telecommunications and electronic commerce. Dallas, Texas, EE.UU.

Burke, K. (2005): «The impact of firm size on Internet use in small businesses», en Electronic Markets, 15, pp. 79-93.

CARÚS, L. (2002): Análisis estratégico comparado de ubicaciones de recreo de alta montaña: Alpes, Rocosas y Pirineo de Lérida. Lleida: Patronato de Turismo de la Diputación.

CHAFFEY, D., MAYER, R., JOHNSTON, K. y ELLIS-CHADWOCK, F. (2003): Internet marketing: strategy, implementation and practice, London: Prentice Hall Financial Times.

CMTNM (2010): «Reinventar el turismo de nieve y montaña para atraer nuevos clientes», en $6^{\circ}$ Congreso Mundial de Turismo de Nieve y Montaña, Andorra la Vella. Consulta 10/01/2015 en http://www.congresdeneu.ad/

CMTNM (2014): «Mountainlikers: nuevas tendencias del turismo de montaña en verano», en $8^{\circ}$ Congreso Mundial de Turismo de Nieve y Montaña, Andorra la Vella. Consulta 10/01/2015 en http://www.congresdeneu.ad/

CONFEDERACIÓN PIRENAICA DE TURISMO (2014): Observatorio de la confederación pirenaica de turismo. Consulta 22/02/2014 en: http://www.pyrenees.net

CONFEDERACIÓN PIRENAICA DE TURISMO (2015): Observatorio de la confederación pirenaica de turismo. Consulta 26/01/2015 en: http://www.pyrenees.net

DOOLIN, B., BURGUESS, L. y COOPER, J. (2002): «Evaluating the use of the Web of tourism marketing: a case study from New Zealand», en Tourism Management, 23, 557-561.

ESTEVE, R. y FUENTES, R. (2000): Economía, historia e instituciones del turismo en España, Madrid: Pirámide.

FERNÁNDEZ-CAVIA, J. y HUERTAS-ROIG, A. (2009): «City brands and their communication through Web sites: identification of problems and proposals for improvement», en Gascó-Hernández, M. y Torres-Coronas, T. (Ed.), Information Communication Technologies and City Marketing. Digital opportunities for cities around the world. Hershey: Information Science Reference.

FUNDACIÓN ORANGE (2007): e-España 2007. Informe anual sobre el desarrollo de la sociedad de la información en España, Madrid. 
GARCIA, O. y ESCALERA, G. (2008): «El uso de los sitios Web en las estaciones de esquí y montaña en España y Andorra», en Congreso TURITEC, Málaga, España.

GOLDSMITH, R.E. (2006): «Electronic Word of Mouth», en Khosrowpour, M. (Ed.), Enciclopedia of e-Commerce, e-Government and Mobile Commerce. Hershey, PA: Idea Group Publishing.

GRETZEL, U., FESENMAIER, D.R., FORMICA, S. y O’LEARY, J.T. (2006): «Searching for the future: challenges faced by destination marketing organizations», en Journal of Travel Research, 45 (2), pp. 116-126.

GÜELL, J.M., MORATO, A. y RODRIGUEZ A. (2005): Estudio de prospectiva del sector turismo. Escenarios de demanda global y tendencias tecnológicas, Madrid: Fundación OPTI y AINIA.

HALL, C.M. (2000): Tourism planning: policies, processes and relationship, Harlow: Prentice Hall.

HAYS, S., PAGE, S.J. y BUHALIS, D. (2012): «Social media as a destination marketing tool: its use by national tourism organisations». Consulta 25/02/2015 en http://dx.doi. org/10.1080/13683500.2012.662215

HO, C. y LEE, Y. (2007): «The development of an e-travel service quality scale», en Tourism Management, 28 (6), pp. 1434-1449.

HO, J.K. (2002): «Easy-to-use multilingual communication. Over the Internet: facilitating e-business for the hotel industry», en Cornell Hotel and Restaurant Administration, 43 (2), pp. 18-25.

HUIZINGH, E. (2000): «The content and design of Web sites: an empirical study» en Information \& Management, 37 (3), pp. 123-134.

ICTE. Instituto para la Calidad Turística Española (2015): Establecimientos certificados. Consulta 26/01/2015 en http://www.calidadturistica.es/

INE. Instituto Nacional de Estadística (2014): Cuenta satélite del turismo de España. Base 2000. Consulta 22/07/2014 en http://www.ine.es/inebase/

KOTLER, P., BOWEN, J., MAKENS, J., RUFIN, R. y REINA, M.D. (2004): Marketing para Turismo, Englewood Cliffs: Prentice Hall.

LAW, R., QI, S. y BUHALIS, D. (2010): «A review of Website evaluation in tourism research», en Tourism Management, 31, pp. 221-234.

MAÑÁ, F. y ESCOBAR, M. (2005): Conectividad, convergencia, seguridad e integración. Un marco para la evolución de las TIC. Madrid: Fundación OPTI e ICT.

MERINERO, R. y NAVARRO, C. (2010): Las ciudades medias del interior de Andalucía: hacia una participación activa en el escenario turístico andaluz. Sevilla: Consejería de Turismo, Comercio y Deporte.

MONTANER, J. (2001): Estructura del mercado turístico, Madrid: Síntesis.

MORRISON, A.M., TAYLOR, S. y DOUGLAS, A. (2004): «Website evaluation in tourism and hospitality», en Journal of Travel and Tourism Marketing, 17 (2), pp. 232-251.

OMC. ORGANIZACIÓN MUNDIAL DEL COMERCIO (1999): Business Council. Consulta 25/02/2014 en http://www.wto.org/

OMT. ORGANIZACIÓN MUNDIAL DE TURISMO (2015): Fiturgreen 2015: el desarrollo sostenible desde la perspectiva del viajero. Consulta 26/01/2015 en http://media. unwto.org/ 
OMT. ORGANIZACIÓN MUNDIAL DEL TURISMO (1998): «El turismo emerge como un sector clave en el marco de la actividad económica internacional», en El turismo como actividad económica. Introducción al turismo, 9-38. Madrid.

OMT. ORGANIZACIÓN MUNDIAL DEL TURISMO (2015): Barómetro OMT del turismo mundial. Consulta 31/01/2015 en http://media.unwto.org/es/pressrelease/2015-01-27/

ONTSI. OBSERVATORIO NACIONAL DE LAS TELECOMUNICACIONES Y DE LA SI (2014): Informe anual. La sociedad en red 2013. Consulta 12/08/2014 en http:// www.ontsi.red.es/ontsi/es/estudios-informes

PALLAS, J. y ECONOMIDES, A.A. (2008): «Evaluation of art museums Web sites worldwide», en IOS Press, 28 (1), pp. 45-57.

PALMER, A. (2005): «The Internet challenge for destination marketing organizations», en Morgan, N., Pritchard, A. y Pride, R. (Ed.) Destination branding: creating the uniquedestination preposition, pp. 128-140. Oxford: Elsevier.

PAN, B., MACLAURIN, T. y CROTTS, J.C. (2007): «Travel blogs and the implications for destination marketing», en Journal of Travel Research, 46 (1), pp. 35-45.

SCHMIDT, S. (2006): Evaluación de los sitios Web de los hoteles e implicaciones para gestión del marketing hotelero, Palma de Mallorca: Universitat de les Illes Balears.

SKI ANDORRA (2014): Consulta 22/02/2014 en http://www.skiandorra.ad/

SKI ANDORRA (2015): Consulta 26/01/2015 en http://www.skiandorra.ad/

STEPHEN, A.T. y LEHMANN, D.R. (2009): Why do people transmit word-of-mouth? the effects of recipient and relationship characteristics on transmission behaviours. Working Paper, Columbia University.

TEO, T.S.H. y PIAN, Y. (2003): «A model for Web adoption», en Information \& Management, 41, 4, pp. 457-468.

TIMMERS, P. (1998): «Business models for electronic markets», en Electronic markets, 8 (2), pp. 3-8.

TURESPAÑA (2007): Plan de objetivos para la promoción exterior del turismo. Plan 2007. Madrid.

TURESPAÑA (2012): Plan nacional e integral de turismo 2012-2015. Consulta 20/02/2014 en http://www.tourspain.es/es-es/vde/paginas/pnit.aspx

TURESPAÑA (2015): Turismo en cifras. Año 2013. Consulta 26/01/2015 en http://www. iet.turismoencifras.es/

VOGELER, C. y HERNÁNDEZ, E. (1997): Estructura y organización del mercado turístico, Madrid: Ed. Centro de Estudios Ramón Areces.

WANG, F., HEAD, M. y ARTHUR, N. (2002): «e-Tailing: an analysis of Web impacts on the retail market», en Journal of Business Strategies, 19 (1), pp. 73-93.

YEUNG, W.L. y LU, M.T. (2004): «Functional characteristics of commercial Web sites: a longitudinal study in Hong Kong», en Information \& Management, 41(3), pp. 483-495.

ZACH, F., XIANG, Z. y FESENMAIER, D.R. (2007): «An assessment of innovation in Web marketing: investigating american convention and visitors bureaus», en Sigala, M., Mich, L. y Murphy, J. (Ed.), Information and Communication Technologies in Tourism 2007, pp. 365-376. Wien/NY: Springer-Verlag. 
Anexo 1

SITIOS WEB ANALIZADOS

\begin{tabular}{|c|c|c|c|c|}
\hline País & Estación & $\begin{array}{c}1^{\mathrm{a}} \\
\text { Observación }\end{array}$ & $\begin{array}{c}2^{\mathrm{a}} \\
\text { Observación }\end{array}$ & Sitio Web \\
\hline 1 España & Manzaneda & $12-03-10$ & 01-03-14 & http://www.manzaneda.com/ \\
\hline 2 España & Valgrande - Pajares & $12-03-10$ & $01-03-14$ & http://www.valgrande-pajares.com \\
\hline 3 España & Fuentes de Invierno & $12-03-10$ & 01-03-14 & http://www.fuentesinvierno.com \\
\hline 4 España & San Isidro & $12-03-10$ & 01-03-14 & http://www.dipuleon.es/estacionsanisidro \\
\hline 5 España & Leitariegos & $12-03-10$ & 01-03-14 & http://www.dipuleon.es/estacionleitariegos \\
\hline 6 España & Alto Campoo & $12-03-10$ & 01-03-14 & http://www.altocampoo.com/ \\
\hline 7 España & Navacerrada & $12-03-10$ & $01-03-14$ & http://www.puertonavacerrada.com/ \\
\hline 8 España & La Pinilla & $12-03-10$ & $01-03-14$ & http://www.lapinilla.es \\
\hline 9 España & La Covatilla & $12-03-10$ & $01-03-14$ & http://www.sierradebejar-lacovatilla.com/ \\
\hline 10 España & Valdesquí & $12-03-10$ & $01-03-14$ & http://www.valdesqui.es \\
\hline 11 España & Valdezcaray & $12-03-10$ & $01-03-14$ & http://www.valdezcaray.es/ \\
\hline 12 España & Sierra Nevada & $12-03-10$ & $01-03-14$ & http://www.sierranevada.es \\
\hline 13 España & Puerto de la Ragua & $12-03-10$ & $01-03-14$ & http://www.puertodelaragua.com \\
\hline 14 España & Astún & $13-03-10$ & $02-03-14$ & http://www.astun.com/ \\
\hline 15 España & Candanchú & $13-03-10$ & $02-03-14$ & http://www.candanchu.com/ \\
\hline 16 España & Cerler & $13-03-10$ & $02-03-14$ & http://www.cerler.com/ \\
\hline 17 España & Formigal & $13-03-10$ & $02-03-14$ & http://www.formigal.com/ \\
\hline 18 España & Javalambre & $13-03-10$ & $02-03-14$ & http://www.javalambre.com/ \\
\hline 19 España & Panticosa-Los Lagos & $13-03-10$ & $02-03-14$ & http://www.panticosa-loslagos.com \\
\hline 20 España & Valdelinares & $13-03-10$ & $02-03-14$ & http://www.valdelinares.com/ \\
\hline 21 España & Roncalia & $13-03-10$ & $02-03-14$ & http://www.roncalia.com/es/invierno/presentacion.php \\
\hline 22 España & Candanchú - Le Somport & $13-03-10$ & $02-03-14$ & http://www.candanchu.com/ \\
\hline 23 España & Llanos del Hospital & $13-03-10$ & $02-03-14$ & http://www.llanosdelhospital.com \\
\hline 24 España & Boi Taüll & $13-03-10$ & $02-03-14$ & http://www.boitaullresort.es/ \\
\hline 25 España & Baqueira & $13-03-10$ & 02-03-14 & http://www.baqueira.es/ \\
\hline 26 España & Granpallars Port Ainé & $13-03-10$ & $02-03-14$ & http://www.skipallars.cat/cms/estacio-port-aine_9/ \\
\hline 27 España & Port del Compte & $13-03-10$ & $02-03-14$ & http://www.portdelcomte.net/ \\
\hline 28 España & Granpallars Espot Esquí & $13-03-10$ & $02-03-14$ & http://www.skipallars.cat/cms/estacio-espot-esqui_3/ \\
\hline 29 España & Granpallars Tavascán & $13-03-10$ & $02-03-14$ & http://www.tavascan.net/ \\
\hline 30 España & La Molina & $13-03-10$ & 02-03-14 & http://www.lamolina.com/ \\
\hline 31 España & Masella & $13-03-10$ & 02-03-14 & http://www.masella.com/ \\
\hline 32 España & Vall de Nuria & $13-03-10$ & $02-03-14$ & http://www.valldenuria.com/ \\
\hline 33 España & Vallter 2000 & $13-03-10$ & 02-03-14 & http://www.vallter2000.com \\
\hline 34 España & Lles & $13-03-10$ & 02-03-14 & http://www.lles.net \\
\hline 35 Andorra & Grandvalira & $13-03-10$ & $02-03-14$ & http://www.grandvalira.com \\
\hline
\end{tabular}

Cuadernos de Turismo, 38, (2016), 167-190 


\begin{tabular}{|c|c|c|c|c|c|}
\hline 36 & Andorra & Vallnord & $13-03-10$ & $02-03-14$ & http://www.vallnord.com \\
\hline 37 & Francia & Artouste & $14-03-10$ & 03-03-14 & http://www.altiservice.com/es/artouste \\
\hline 38 & Francia & Ascou & $14-03-10$ & 03-03-14 & http://www.ascou-ski.com/ \\
\hline 39 & Francia & Ax-3 Domaines & $14-03-10$ & 03-03-14 & http://www.ax-ski.com/ \\
\hline 40 & Francia & Camurac & $14-03-10$ & 03-03-14 & http://www.cc-pays-de-sault.fr/ \\
\hline 41 & Francia & Cuaterets & $14-03-10$ & 03-03-14 & http://www.cauterets.com/ \\
\hline 42 & Francia & Espace Cambre d'Aze & $15-03-10$ & 04-03-14 & http://www.cambre-d-aze.com/ \\
\hline 43 & Francia & Font-Romeu Pyrénées 2000 & $15-03-10$ & 04-03-14 & http://www.fontromeu-pyrenees2000.com/ \\
\hline 44 & Francia & Formiguères & $15-03-10$ & 04-03-14 & http://www.formigueres.fr/ \\
\hline 45 & Francia & Gavarnie-Gèdre & $14-03-10$ & 03-03-14 & http://hiver.gavarnie.com/ \\
\hline 46 & Francia & Goulier-Neige & $14-03-10$ & 03-03-14 & http://www.pays-du-montcalm.com/fr/ \\
\hline 47 & Francia & Gourette & $15-03-10$ & 04-03-14 & http://www.n-py.com/fr/hiver/gourette/presentation.htm \\
\hline 48 & Francia & Grand Tourmalet - Pic du Midi & $14-03-10$ & 03-03-14 & http://www.grand-tourmalet.com/fr/index.aspx \\
\hline 49 & Francia & Guzet & $14-03-10$ & 03-03-14 & http://www.altiservice.com/guzet \\
\hline 50 & Francia & Hautacam & $14-03-10$ & 03-03-14 & http://www.hautacam.com/ \\
\hline 51 & Francia & La Pierre - Saint Martin & $15-03-10$ & 04-03-14 & http://www.lapierrestmartin.com/fr/index.aspx \\
\hline 52 & Francia & Le Mourtis & $14-03-10$ & 03-03-14 & http://mourtis.fr/ \\
\hline 53 & Francia & Les Angles & $15-03-10$ & 04-03-14 & http://www.lesangles.com/fr \\
\hline 54 & Francia & Les Monts d'Olmes & $14-03-10$ & $03-03-14$ & http://www.montsdolmes.com/ \\
\hline 55 & Francia & Luchon . Superbagnères & $14-03-10$ & 03-03-14 & http://www.luchon.com/ \\
\hline 56 & Francia & Luz - Ardiden & $15-03-10$ & 04-03-14 & http://www.luz.org/ \\
\hline 57 & Francia & Mijanès - Donezan & $14-03-10$ & 03-03-14 & http://www.donezan.com/ \\
\hline 58 & Francia & Peyragudes & $14-03-10$ & 03-03-14 & http://www.peyragudes.com/ \\
\hline 59 & Francia & Piau - Engaly & $15-03-10$ & 04-03-14 & http://www.piau-engaly.com/ \\
\hline 60 & Francia & Porté - Puymorens & $15-03-10$ & 04-03-14 & http://www.porte-puymorens.net/ \\
\hline 61 & Francia & Puyvalador & $15-03-10$ & 04-03-14 & http://www.puyvalador.com/ \\
\hline 62 & Francia & Saint-Lray Soulan & $14-03-10$ & 03-03-14 & http://www.saintlary.com/ \\
\hline 63 & Francia & Val Louron & $15-03-10$ & 04-03-14 & http://www.val-louron-ski.com/ \\
\hline 64 & Francia & Beille & $15-03-10$ & 04-03-14 & http://www.beille.fr/ \\
\hline 65 & Francia & Capcir & $15-03-10$ & 04-03-14 & http://www.capcir-nordique.com/ \\
\hline 66 & Francia & Cauterets Pont d'Espagne & $15-03-10$ & 04-03-14 & http://www.cauterets.com/ \\
\hline 67 & Francia & Etang de Lers & $15-03-10$ & 04-03-14 & http://www.etang-de-lers.fr/ \\
\hline 68 & Francia & Font-Romeu Purénées 2000 & $15-03-10$ & 04-03-14 & http://www.fontromeu-pyrenees2000.com/ \\
\hline 69 & Francia & Grand Tourmalet Campan-Payolle & $15-03-10$ & 04-03-14 & http://www.grand-tourmalet.com/fr/index.aspx \\
\hline 70 & Francia & Hautacam & $15-03-10$ & 04-03-14 & http://www.hautacam.com/ \\
\hline & Francia & Iraty & $15-03-10$ & 04-03-14 & http://www.chalets-iraty.com/ \\
\hline 72 & Francia & Issarbe & $15-03-10$ & 04-03-14 & $\begin{array}{l}\text { http://www.lapierrestmartin.com/pyrenees/-Espace- } \\
\text { nordique-d-Issarbe }\end{array}$ \\
\hline 73 & Francia & La Pierre-Saint-Martin & $15-03-10$ & 04-03-14 & http://www.lapierrestmartin.com/fr/index.aspx \\
\hline
\end{tabular}




\begin{tabular}{|c|c|c|c|c|c|}
\hline 74 & Francia & Le Chioula & $15-03-10$ & 04-03-14 & http://www.chioula.fr/ \\
\hline 75 & Francia & Le Somport-Candanchu & $15-03-10$ & 04-03-14 & http://www.lesomport.com/ \\
\hline 76 & Francia & Mijanès - Donezan & $15-03-10$ & 04-03-14 & http://www.donezan.com/ \\
\hline 77 & Francia & Nistos & $15-03-10$ & 04-03-14 & http://www.nistos-ski.fr/ \\
\hline 78 & Francia & Val d'Azun & $15-03-10$ & 04-03-14 & http://www.valdazun.fr/ \\
\hline
\end{tabular}

Fuente: elaboración propia a partir de ATUDEM (2014), SKI ANDORRA (2014) y LES PYRÉNÉES (2014). 